\title{
An amperometric L-tryptophan sensor platform based on electrospun tricobalt tetroxide nanoparticles decorated carbon nanofibers
}

Zhao Dongsheng ${ }^{1}$, Lu Youlan $^{1}$, Ding Yaping ${ }^{\mathrm{a}, \mathrm{b}}$, Fu Rong

a. School of Materials Science and Engineering, College of Science, Shanghai University, Shangda Raod, Baoshan District, Shanghai 200444, P.R.C

b. Shanghai Key Laboratory of High Temperature Superconductors, Shanghai University, Shangda Raod, Baoshan District, Shanghai 200444, P.R.C

\section{Abstract:}

A glassy carbon electrode (GCE) modified with electropun tricobalt tetroxide nanoparticles decorated carbon nanofibers $\left(\mathrm{Co}_{3} \mathrm{O}_{4}\right.$-CNF $)$ were first applied for the determination of L-tryptophan (L-Trp). The synthesized $\mathrm{Co}_{3} \mathrm{O}_{4}$-CNF were characterized by scanning electron microscopy, Raman, X-ray diffraction and electrochemical impedance spectroscopy. The electrochemical detection of L-try was successfully conducted in $0.1 \mathrm{M}$ phosphate solution (pH 2).

The linear relationship of L-Trp was in the range of $0.005-40 \mu \mathrm{M}$ and the detection limit reached $0.002 \mu \mathrm{M}(\mathrm{S} / \mathrm{N}=3)$ with little interference from other amino acids.

Keywords: tricobalt tetroxide nanoparticles, carbon nanofibers, L-tryptophan, electrochemical determination

\footnotetext{
${ }^{*}$ Corresponding author: Tel: +86-21-66134734; Fax: +86-21-66132797
}

Address: College of Science, Shanghai University, Shanghai 200444, PR China

E-mail address: wdingyp@ sina.com 


\section{Introduction:}

L-tryptophan (L-Trp) is an essential amino acid for normal growth in infants and nitrogen balance in adults ${ }^{[1]}$. In many biochemical process, L-Trp serves as a precursor or a vital element for forming neurotransmitter as serotonin or neurohormones as melatonin and $\operatorname{niacin}^{[2]}$. As an essential amino acid, L-tryptophan can be only obtained through food or medical supplementation. However, the large quantity and improper metabolized of L-Trp in body can cause side effects as agitation, fever, or even diseases as hallucination, delusion etc ${ }^{[3]}$. Therefore, the detection of L-Trp is significant in many field as food processing, bio-chemistry, pharmaceuticals, clinical analysis, etc ${ }^{[4]}$.

Various methods have been developed for the determination of L-Trp, such as high-performance liquid chromatography ${ }^{[5]}$, fluorescence spectroscopy ${ }^{[6]}$, capillary electrophoresis ${ }^{[7]}$ as well as electroanalysis ${ }^{[8]}$. Among these methods, electrochemical method has attracted the interest of researches because of L-Trp's inherent electroactivity behavior caused by its aromatic group ${ }^{[9]}$ and the merits of electroanlysis as high sensitivity, time-saving and simple operation ${ }^{[10]}$. Due to the sluggish electron transfer process and over-potential of $\mathrm{L}^{-T_{r}}{ }^{[11]}$, different modified electrodes have been reported for the determination of L-Trp. These modified electrodes are capable in promoting the kinetics of electron transfer process and reducing the over-potential of L-Trp in the electro-oxidation ${ }^{[12]}$. Cobalt-based nanoparticles decorated carbon based materials stand out due to their superior catalytic performances ${ }^{[13]}$. For instance, Ali et.al synthesized a cobalt ferrite nanohybrid on exfoliated graphene oxide compound, which shown synergetic effect towards the electro-reduction of $\mathrm{H}_{2} \mathrm{O}_{2}$ and nicotinamide adenine dinucleotide ${ }^{[14]}$. Mujtaba et. al. decorated porous carbon material with $\mathrm{Co}_{3} \mathrm{O}_{4}$, which turned out to be a good lithium ion battery anode 
materials and shown satisfied electron transfer property ${ }^{[15]}$. Qu et. al. used one-step hydrothermal method to modify $\mathrm{Co}(\mathrm{OH})\left(\mathrm{CO}_{3}\right)_{0.5}$ nano-cone arrays on both sides of the thin walls of macroporous carbon nanotubes, that exhibited an improved specific capacitance and high performance as a supercapactiors ${ }^{[16]}$.

Fibrous carbon materials with one dimension on nanoscale as carbon nanofibers (CNF) are increasingly attracting the attention of scientists in recent years. One of the main advantages of $\mathrm{CNF}$ is it's high surface area to volume ratios ${ }^{[17]}$. In addition, carbon based materials possess properties as superior electrical conductivity, relative chemical inertness in most electrolyte solution, wide potential windows in aqueous media made them extremely suitable in constructing electrochemical sensors ${ }^{[18]}$. Also CNF's entire surface can be easily functionalized with nanoscale materials ${ }^{[19]}$. These synthesized $\mathrm{CNF}$ and $\mathrm{CNF}$ based multifunctional hybrids have shown potential applications in the filed as supercapacitor ${ }^{[20]}$, lithium batteries ${ }^{[21]}$, catalyst supports $^{[22]}$, filter $^{[23]}$ as well as chemical sensors ${ }^{[24]}$.

In this work, $\mathrm{Co}_{3} \mathrm{O}_{4}$ nanoparticles decorated carbon nanofibers $\left(\mathrm{Co}_{3} \mathrm{O}_{4}-\mathrm{CNF}\right)$ were synthesized by electrospinning polymer precursor containing different weight percentage of metal salt, followed by successive anneal and oxidation process. The obtained $\mathrm{Co}_{3} \mathrm{O}_{4}-\mathrm{CNF}$ were modified on a glassy carbon electrode (designate as $\mathrm{Co}_{3} \mathrm{O}_{4}-\mathrm{CNF} / \mathrm{GCE}$ ) by electrodeposition technique and it was used in sensitive detection of L-Trp in $0.1 \mathrm{M}$ phosphate solution ( $\mathrm{pH} 2)$ with a wide linear range of $0.005 \mu \mathrm{M}-40 \mu \mathrm{M}$.

\section{Experimental}

\subsection{Apparatus and Chemicals}

Electrochemical measurements including cyclic voltammetry (CV), differential pulse voltammetry 
(DPV) and chronoamperometry were performed on a CHI 842B electrochemical workstation (Chenhua Corp., Shanghai, China). Electrochemical impedance spectroscopy (EIS) was carried on a CHI 660D electrochemical workstation (Chenhua corp., Shanghai, China). A conventional three-electrode cell with a glassy carbon electrode $(\mathrm{GCE}, \phi=3.0 \mathrm{~mm})$ served as the working electrode, a calomel electrode as the reference electrode and a platinum electrode as the counter electrode was employed during electrochemical measurements. Scanning electron graphs were obtained by a scanning electron micrograph (JSM-6700F, $15.0 \mathrm{kV}$ ). Raman scattering was performed on a Raman Microscope (INVIA England) using a $545.5 \mathrm{~nm}$ laser source. XRD analysis was carried out on X-ray diffractometer (Haoyuan DX-2700, China).

Cobalt acetate, PAN, L-Trp, leucine, threonine alanine glucose phenylalanine, lysine, folic acid, uric acid and tyrosine were purchased from Aldrich. N,N-dimethylformamide, potassium chloride, hydrochloric acid and other chemicals were purchased from Sinopharm chemical reagent Co., Ltd. (SCRS, China). All chemicals used in this work were of analytical reagent grade and used without further purification. All experiments were carried in $0.1 \mathrm{M}$ phosphate solution $(\mathrm{pH}=2)$. The drug sample of L-Trp (Tianshi amino acid compound tablets) was purchased from local pharmacy in Shanghai. All electrochemical experiments were carried at room temperature. The standard solutions of L-Trp with different concentration ranged in $1 \times 10^{-5}$ to $1 \times 10^{-2} \mathrm{M}$ was prepared by weight and dissolved in $0.1 \mathrm{M} \mathrm{HCl}$ followed with proper dilution process by double deionized water (DDW).

\subsection{Synthesis of $\mathrm{Co}_{3} \mathrm{O}_{4}$ decorated Carbon nanofibers $\left(\mathrm{Co}_{3} \mathrm{O}_{4}-\mathrm{CNF}\right)$}

The $\mathrm{Co}_{3} \mathrm{O}_{4}$-CNF were synthesized by electrospinning technique followed with a subsequent heating process. The precursor used for electrospining were prepared by dissolving certain weight 
ratio of PAN and cobalt acetate in DMF under magnetic stirring overnight at room temperature to ensure the mixture's homogeneity. Then the prepared precursor was fed into a syringe pump at the flow rate of $1 \mathrm{ml} / \mathrm{h}$. The electrospining process was conducted by applying a voltage of $18 \mathrm{KV}$ between the needle and the aluminum foil collector at a distance of $10 \mathrm{~cm}$. As a control, blank PAN fiber (10 wt $\%$ PAN in DMF) and different weight ratio $\mathrm{Co}_{3} \mathrm{O}_{4}-\mathrm{CNF}$ were also synthesized under the same procedure. For carbonization, the as-prepared fibers were followed by similar procedure which reported before ${ }^{[13]}$. For detail, the as prepared fibers were first heated up from room temperature to $280{ }^{\circ} \mathrm{C}$ at a rate of $3{ }^{\circ} \mathrm{C}$ per minute and stayed in air for $1 \mathrm{~h}$ for shape stabilization. Then heated up to $1000{ }^{\circ} \mathrm{C}$ at rate of $2{ }^{\circ} \mathrm{C} / \mathrm{min}$ under nitrogen protection and stayed at the highest temperature for $2 \mathrm{~h}$. After the calcination process, the synthesized material was reheated to $200^{\circ} \mathrm{C}$ in air and kept the temperature for $2 \mathrm{~h}$ to allow cobalt based nanoparticles transform to $\mathrm{Co}_{3} \mathrm{O}_{4}$ completely. For instance, the $\mathrm{Co}_{3} \mathrm{O}_{4}-\mathrm{CNF}$ obtained from the precursors with different weight percentage of $\mathrm{Co}_{3} \mathrm{O}_{4}$ loaded CNF hybrid were synthesized by adding $2.5 \mathrm{wt} \%$ $\mathrm{Co}(\mathrm{Ac})_{2} \bullet 4 \mathrm{H}_{2} \mathrm{O}, 5 \mathrm{wt} \% \mathrm{Co}(\mathrm{Ac})_{2} \bullet 4 \mathrm{H}_{2} \mathrm{O}$ and $7.5 \mathrm{wt} \% \mathrm{Co}(\mathrm{Ac})_{2} \bullet 4 \mathrm{H}_{2} \mathrm{O}$ in to PAN polymer precursor (10 wt $\%$ PAN in DMF). For convenience, the synthesized materials were noted as $2.5 \mathrm{wt} \%$ $\mathrm{Co}_{3} \mathrm{O}_{4}-\mathrm{CNF}, 5 \mathrm{wt} \% \mathrm{Co}_{3} \mathrm{O}_{4}-\mathrm{CNF}$ and $7.5 \mathrm{wt} \% \mathrm{Co}_{3} \mathrm{O}_{4}-\mathrm{CNF}$, respectively.

\subsection{Preparation of modified electrode}

Before the modification, a bare GCE $(\varphi 3 \mathrm{~mm})$ was firstly polished by $0.05 \mu \mathrm{m}$ alumina slurries until a mirror-like surface was acquired. Then the GCE was cleaned in 1:1(v/v) $\mathrm{HNO}_{3}$ solution, ethanol and DDW under the help of ultrasonic bath. The synthesized $\mathrm{Co}_{3} \mathrm{O}_{4}-\mathrm{CNF}(1 \mathrm{mg} / \mathrm{mL})$ were dispersed in DDW with the help of ultrasonic bath as well. The $\mathrm{Co}_{3} \mathrm{O}_{4}-\mathrm{CNF} / \mathrm{GCE}$ was gained via electrodepositing method by applying a constant potential of $1.8 \mathrm{~V}$ for 400 s in $0.1 \mathrm{M} \mathrm{KCl}$ solution 


\subsection{Characterization of modified electrode}

3.1.1 SEM, XRD and Raman spectroscopy. Fig. 1A shows the SEM image of the morphology and microstructure of the prepared $\mathrm{Co}_{3} \mathrm{O}_{4}$-CNF. The diameter of the synthesized hybrid range from 200 to $400 \mathrm{~nm}$ with tens of micrometers in length. A large amount of bright contract nanoparticles about $100 \mathrm{~nm}$ in size randomly dispersed on the surface of $\mathrm{CNF}$, which are probably derived from the decomposition of cobalt acetate. For comparison, the morphology of $\mathrm{Co}_{3} \mathrm{O}_{4}$ nanoparticles synthesized by the same electrospining technique shown in Fig. 1B. As can be seen from Fig. 1B, the particle size of $\mathrm{Co}_{3} \mathrm{O}_{4}$ range from 100 to $500 \mathrm{~nm}$ and they tend to be aggregated easily. This confirms that the CNF can be served as a catalyst supporter, which avoids nanoparticles from aggregating.

$\mathrm{XRD}$ is a powerful tool to identify the composition of synthesized $\mathrm{Co}_{3} \mathrm{O}_{4}-\mathrm{CNF}$. As shown in Fig. diffraction peaks at about $18^{\circ}, 32^{\circ}, 38^{\circ}, 40^{\circ}, 46^{\circ}, 57^{\circ}, 61^{\circ}, 67^{\circ}, 79^{\circ}$ correspond to (111), (220), (311), (222), (400), (422), (511), (440) and (533) crystalline plane of $\mathrm{Co}_{3} \mathrm{O}_{4}$. The result shows that after the oxidation process, cobalt has been totally transformed to $\mathrm{Co}_{3} \mathrm{O}_{4}$. Raman spectrum is a useful tool to determinate the structure of different materials. As shown in Fig 1D, four characteristic crystalline peaks of $\mathrm{Co}_{3} \mathrm{O}_{4}$ were observed at 463, 505, 606 and 673

131 at $1334 \mathrm{~cm}^{-1}$ and $1579 \mathrm{~cm}^{-1}$ corresponding to the defect induced D band and graphitic $\mathrm{G}$ band of the carbonaceous material ${ }^{[26]}$, respectively. These results indicate the complete transformation of 
electrospun PAN polymeric fibers to conductive CNFs.

Fig 1 here

\subsubsection{Electrochemical properties of $\mathrm{Co}_{3} \mathrm{O}_{4}-\mathrm{CNF}$}

In order to determinate the electrochemical properties of $\mathrm{Co}_{3} \mathrm{O}_{4}$-CNF, a comparison of $10 \mu \mathrm{M}$

L-Trp's current signal on bare GCE, $\mathrm{Co}_{3} \mathrm{O}_{4} / \mathrm{GCE}, \mathrm{CNF} / \mathrm{GCE}$ and $\mathrm{Co}_{3} \mathrm{O}_{4}$-CNF/ GCE was conducted in $0.1 \mathrm{M}$ phosphate solution ( $\mathrm{pH}$ 2) by CV. As shown in Fig 2A, the current signal of 10 $\mu \mathrm{M}$ L-Trp on bare GCE was very low due to the sluggish electron transfer on the surface of bare GCE. The current signal of which was only $0.3058 \mu \mathrm{A}$ and the oxidation potential was as high as $0.9589 \mathrm{~V}$. However, all of three modified electrodes showed catalytic property towards L-Trp that dramatically increased the current signal of $10 \mu \mathrm{M} \mathrm{L}$-Trp. From $\mathrm{b}$ to $\mathrm{d}$, the current signal of $10 \mu \mathrm{M}$ L-Trp was 26.1 times, 50.1 times and 82.2 times higher than that on bare GCE. Meanwhile, the oxidation potential of $\mathrm{L}-\mathrm{Trp}$ on modified electrode was negatively shifted $77.9 \mathrm{mV}$ at $\mathrm{Co}_{3} \mathrm{O}_{4} / \mathrm{GCE}$, $81.9 \mathrm{mV}$ at $\mathrm{CNF} / \mathrm{GCE}$ and $\mathrm{Co}_{3} \mathrm{O}_{4}-\mathrm{CNF} / \mathrm{GCE}$, respectively. These results suggested that both $\mathrm{Co}_{3} \mathrm{O}_{4} / \mathrm{GCE}$, and $\mathrm{CNF} / \mathrm{GCE}$ showed catalytic activity to L-Trp. Among them $\mathrm{Co}_{3} \mathrm{O}_{4}-\mathrm{CNF} / \mathrm{GCE}$ performed the best catalytic ability towards L-Trp because of synergetic effect.

EIS was used for studying the interface characteristic of modified electrode. The typical Nyquist diagrams of bare $\mathrm{GCE}$ and $\mathrm{Co}_{3} \mathrm{O}_{4}-\mathrm{CNF} / \mathrm{GCE}$ in $5.0 \mathrm{mM}\left[\mathrm{Fe}(\mathrm{CN})_{6}\right]^{3-14-}$ solution containing $0.1 \mathrm{M}$ $\mathrm{KCl}$ at the were shown at Fig.2 B. The Nyquist plots consist a semicircular part and a linear part corresponding to the electron transfer controlled process and the diffusion controlled process, respectively. The diameter of the semicircular part at high frequency equals to the charge transfer resistance on the electrode interface. It is shown in Fig. 2B that, the charge transfer resistance of $\mathrm{Co}_{3} \mathrm{O}_{4}$-CNF/GCE is about $50 \Omega$ smaller than that on bare GCE (325 $\Omega$ ) suggesting that the 
synthesized material shown good electrical conducting property. In the meantime, the almost straight line at lower frequencies on $\mathrm{Co}_{3} \mathrm{O}_{4}-\mathrm{CNF} / \mathrm{GCE}$ suggested a diffusion controlled process was the main controlled process during the reaction.

Fig. 2 here

\subsection{Electrochemical behaviors of L-Trp on $\mathrm{Co}_{3} \mathrm{O}_{4}-\mathrm{CNF} / G C E$}

For studying electrochemical behavior of L-Trp on $\mathrm{Co}_{3} \mathrm{O}_{4}-\mathrm{CNF} / \mathrm{GCE}$, the effect of scan rate was investigated by $\mathrm{CV}$ at modified GCE in $0.1 \mathrm{M}$ phosphate solution ( $\mathrm{pH} 2)$ containing $10 \mu \mathrm{M}$ L-Trp. The scan rate were set in the range of $10-200 \mathrm{mV} \mathrm{s}^{-1}$. As can been seen from Fig. 3, the oxidation peak currents of L-Trp rose with the increase of scan rate, at the same time the oxidation peak current showed a good linear relationship with scan rate $v^{1 / 2}$. The linear regression of the oxidation peak current and the scan rate could be expressed as $I_{p a}(\mu A)=1.775 v^{1 / 2}-4.469(R=0.997)$, indicating the electro-oxidation reactions of L-Trp is a diffusion controlled process. Furthermore, with the increase of scan rate, $E_{p}$ shifted positively. The dependence of $E_{p}$ with $\log v$ could be expressed as $E_{p}(V)=0.06379 \log v+0.7667(R=0.999)$. According to Lavrion's theory, the slop equals to $2.303 \mathrm{RT} /(1-\alpha) \mathrm{nF}^{[27]}$. As for an irreversible electrode process, the electron transfer coefficient $\alpha$ can be assumed as 0.5 , the number of the electrons involved in the rate determining step was calculated to be 1.85 , which is in agreement to previous reports. So that the overall oxidation process of L-Trp is 2 electron involved process and the mechanism of the reaction can be deducted as scheme 1 .

Fig. 3. here

Scheme1 here

\subsection{Effect of operational parameters}




\subsubsection{Effect of $\mathrm{Co}_{3} \mathrm{O}_{4}$ loading amount}

In this work different $\mathrm{Co}_{3} \mathrm{O}_{4}$ loading amount on $\mathrm{CNF}$ has been studied in order to understand the mechanical property and the catalytic property of the synthesized material. Fig S1 shows SEM photos of $2.5 \mathrm{wt} \% \mathrm{Co}_{3} \mathrm{O}_{4}-\mathrm{CNF}, 5 \mathrm{wt} \% \mathrm{Co}_{3} \mathrm{O}_{4}-\mathrm{CNF}$ and $7.5 \mathrm{wt} \% \mathrm{Co}_{3} \mathrm{O}_{4}-\mathrm{CNF}$. It can be seen from Fig. S1 A to Fig. S1 F, the more cobalt acetate added into the precursor, the more tendency that CNF became shorter. When the weight percentage of $\mathrm{Co}(\mathrm{Ac})_{2} \bullet 4 \mathrm{H}_{2} \mathrm{O}$ reached $7.5 \mathrm{wt} \%$ in the precursor, the length of CNF compromised greatly. In order to study the effect of morphology, the current signal of $10 \mu \mathrm{M}$ L-Trp was tested on these three modified electrodes. Fig. S2 is CV pattern of $10 \mu \mathrm{M}$ L-Trp on $2.5 \mathrm{wt} \% \mathrm{Co}_{3} \mathrm{O}_{4}-\mathrm{CNF}, 5 \mathrm{wt} \% \mathrm{Co}_{3} \mathrm{O}_{4}-\mathrm{CNF}$ and $7.5 \mathrm{wt} \% \mathrm{Co}_{3} \mathrm{O}_{4}-\mathrm{CNF}$. L-Trp shows an irreversible oxidation on modified electrodes the current signal of L-Trp peaked at 5 wt $\%$ $\mathrm{Co}_{3} \mathrm{O}_{4}-\mathrm{CNF}$ and the current signal is 1.1 and 1.3 times higher than that on $2.5 \mathrm{wt} \% \mathrm{Co}_{3} \mathrm{O}_{4}-\mathrm{CNF}$ and $7.5 \mathrm{wt} \% \mathrm{Co}_{3} \mathrm{O}_{4}-\mathrm{CNF}$ which means the synthesized $5 \mathrm{wt} \% \mathrm{Co}_{3} \mathrm{O}_{4}-\mathrm{CNF}$ shown the highest catalytic property towards L-Trp.

\subsubsection{Effect of $\mathrm{pH}$ values.}

The relationship between $\mathrm{pH}$ and peak current of L-Trp was illustrated in Fig. 4A to B. As it can be seen that the oxidation current peaked at $\mathrm{pH} 2$ and then decrease with the increase of $\mathrm{pH}$ value. Besides, the oxidation potential of L-Trp at $\mathrm{Co}_{3} \mathrm{O}_{4}-\mathrm{CNF}$ shifted negatively with the increase of $\mathrm{pH}$, which means the oxidation process associated with proton-transfer. A linear dependence between potentials and $\mathrm{pH}$ for $\mathrm{L}-\mathrm{Trp}$ was as follow: $\mathrm{E}_{\mathrm{p}}(\mathrm{V})=0.04614 \mathrm{pH}+0.9716(\mathrm{R}=0.997)$.

\subsubsection{Effect of electro-deposition potential}

The effect of electro-deposition potential in the nature of proposed sensor is considerable important. The test was carried out in $10 \mathrm{~mL} 0.1 \mathrm{M} \mathrm{KCl}$ containing $200 \mu \mathrm{L} 1 \mathrm{mg} / \mathrm{mL} 5 \mathrm{wt} \%$ 
199

200

201

202

203

204

205

206

207

208

209

210

211

212

213

214

215

$\mathrm{Co}_{3} \mathrm{O}_{4}-\mathrm{CNF}$ solution and deposition potential was implemented from 1.6-2.0 V. As shown in Fig.

4D $10 \mu \mathrm{M}$ L-Trp current signal peaked when deposition potential reached $1.8 \mathrm{~V}$ and then decrease with the increase of deposition potential. As a result, $1.8 \mathrm{~V}$ was chosen to be the optimized deposition potential.

Fig. 4 here

\subsection{Calibration curve of L-Trp}

I-T was selected to explore the linear relationship between concentration of L-Trp and the oxidation current under optima condition. $0.85 \mathrm{~V}$ was chosen to be the applied potential. As shown in Fig. 5 the current response increased linearly with successive addition of L-Trp into the stirring phosphate solution $(\mathrm{pH} 2)$ at the range of $0.005 \mu \mathrm{M}-40 \mu \mathrm{M}$. The linear regression was $\mathrm{I}_{\mathrm{p}}(\mu \mathrm{A})=$ $0.06895+0.1594 \mathrm{C}(\mu \mathrm{M})(\mathrm{R}=0.996)$. The detection limit is estimated to be $2.0 \times 10^{-9} \mathrm{~mol} \mathrm{~L}^{-1}$ $(\mathrm{S} / \mathrm{N}=3)$. Table 1 lists the comparison of $\mathrm{Co}_{3} \mathrm{O}_{4}$-CNF/GCE with other carbon based sensors reported before. Our work shows a good linear working range and an attractive detection limit.

Fig 5 here

Table 1 here

\subsection{Interference, reproducibility and stability of the sensor}

Selectivity is a major parameter in judging the practicability of the proposed sensor. In supplementary pills, other amino acids like leucine, threonine, alanine, phenylalanine, lysine and saccharides as glucose and sucrose usually coexist with L-Trp. Table 2 shows the results of interference experiments of those coexisting component on the current intensity of $10 \mu \mathrm{M} \mathrm{L}-$ tryptophan on $\mathrm{Co}_{3} \mathrm{O}_{4}-\mathrm{CNF} / \mathrm{GCE}$. As it can be seen from the table, the sensing platform can distinguish well L-Trp from other coexisting interference. For further interferences as folic acid 
and uric acid to L-Trp, those results can be found in Fig. S3.

Table 2 here

The reproducibility and stability of proposed sensor have been studied through 6 successive measurement in the $10 \mu \mathrm{M}$ L-Trp solution on different modified electrode. The relative standard deviation of the current signal was calculated to be $3.8 \%$, which confirmed the reliability and reproducibility of the $\mathrm{Co}_{3} \mathrm{O}_{4}-\mathrm{CNF} / \mathrm{GCE}$. The stability of the proposed sensor was studied after storing the proposed electrode 20 days in room temperature. The current signal of $10 \mu \mathrm{M} L-\operatorname{Trp}$ only $4 \%$ less compared by new synthesized electrode. So that our proposed electrode shown a relatively long store life.

\subsection{Real samples analysis}

The practical utility of $\mathrm{Co}_{3} \mathrm{O}_{4}-\mathrm{CNF} / \mathrm{GCE}$ was evaluated by employing it for the determination of L-Trp in pills that purchased from local pharmacy (Tianshi muliti-amino acid pills). The concentration of L-Trp was estimated by standard addition method. The amperometric response of L-Trp was recorded at $\mathrm{Co}_{3} \mathrm{O}_{4}-\mathrm{CNF} / \mathrm{GCE}$ and the results were displayed in table 3 . From the quantitative recovery results, the $\mathrm{Co}_{3} \mathrm{O}_{4}-\mathrm{CNF} / \mathrm{GCE}$ can be successfully employed for the determination of L-Trp in medicine sample.

Table 3 here

\section{Conclusion}

In this work, a simple and effective method for the quantification of L-Trp was investigated by electrochemical method on a $\mathrm{Co}_{3} \mathrm{O}_{4}-\mathrm{CNF} / \mathrm{GCE}$. SEM and XRD result demonstrated the morphology and chemical component of synthesized materials. The synthesized $\mathrm{Co}_{3} \mathrm{O}_{4}-\mathrm{CNF} / \mathrm{GCE}$ shown good catalytic property towards L-Trp, at the same time it shown a wide linear range and a 
243

good anti-interference property towards other amino acids. The detection limit of L-Trp on the proposed electrode was $2.0 \times 10^{-9} \mathrm{~mol} \mathrm{~L}^{-1}$ and it performed good accuracy in real samples’ test.

\section{Acknowledgements}

This research is supported by the National Science Foundation of China (No. 21271127) and partly supported by Shanghai Key laboratory of High Temperature Superconductors (No.14DZ2260700) for financial supports.

Lu Youlan and Zhao Dongsheng these two authors contributed equally to this work and should be considered as co-first authors.

Reference

[1] K. Q. Deng, J. H. Zhou and X. F. Li, Colloids Surf B Biointerfaces 2013, 101, 183-188.

[2] S. Boonchiangma, S. Srijaranai, T. Tuntulani and W. Ngeontae, Journal of Applied Polymer Science 2014, 40356, 1-8.

[3] K. Rajalakshmi and S. Abraham John, Journal of Electroanalytical Chemistry 2014, 734, 31-37.

[4] Z. Zhang, S. Gu, Y. Ding, J. Jin and F. Zhang, Analytical Methods 2013, 5, 4859.

[5] E. Henykova, H. P. Vranova, P. Amakorova, T. Pospisil, A. Zukauskaite, M. Vlckova, L. Urbanek, O. Novak, J. Mares, P. Kanovsky and M. Strnad, J Chromatogr A 2016, 1437, 145-157.

[6] L. Jiao, S. Bing, X. Zhang, Y. Wang and H. Li, Anal. Methods 2015, 7, 4535-4540.

[7] F. J. Gomez, A. Martin, M. F. Silva and A. Escarpa, Electrophoresis 2015, 36, 1880-1885.

[8] X. Liu, L. Luo, Y. Ding and D. Ye, Bioelectrochemistry 2011, 82, 38-45.

[9] H. Liu, Y. Chen, Y. Liu and Z. Yang, Journal of Solid State Electrochemistry 2013, 17, 2623-2631. 
265

266

267

268

269

270

271

272

273

274

275

276

277

278

279

280

281

282

283

284

285

286

[10] X. Ba, L. Luo, Y. Ding and X. Liu, Sensors and Actuators B: Chemical 2013, 187, 27-32.

[11] S. M. MacDonald and S. G. Roscoe, Electrochimica Acta 1997, 42, 1189-1200.

[12] Y. Wang, X. Ouyang, Y. Ding, B. Liu, D. Xu and L. Liao, RSC Adv. 2016, 6, 10662-10669.

[13] B. Li, X. Ge, F. W. Goh, T. S. Hor, D. Geng, G. Du, Z. Liu, J. Zhang, X. Liu and Y. Zong, Nanoscale 2015, 7, 1830-1838.

[14] A. A. Ensafi, H. A. Alinajafi, M. Jafari-Asl, B. Rezaei and F. Ghazaei, Mater Sci Eng C Mater Biol Appl 2016, 60, 276-284.

[15] J. Mujtaba, H. Sun, G. Huang, K. Molhave, Y. Liu, Y. Zhao, X. Wang, S. Xu and J. Zhu, Sci Rep 2016, 6, 20592.

[16] Y. Qu, G. Zan, J. Wang and Q. Wu, J. Mater. Chem. A 2016, 4, 4296-4304.

[17] J. Liwen, A. J. Medford and Z. Xiangwu, Journal of Materials Chemistry 2009, 19, 5593.

[18] J. Huang, Y. Liu and T. You, Analytical Methods 2010, 2, 202-211.

[19] L. Matlock-Colangelo and A. J. Baeumner, Lab Chip 2012, 12, 2612-2620.

[20] L. Zhang, Q. Ding, Y. Huang, H. Gu, Y.-E. Miao and T. Liu, ACS Applied Materials \& Interfaces 2015, 7, 22669-22677.

[21] E. S. Pampal, E. Stojanovska, B. Simon and A. Kilic, Journal of Power Sources 2015, 300, $199-215$.

[22] H. Kunitomo, H. Ishitobi and N. Nakagawa, Journal of Power Sources 2015, 297, 400-407.

[23] J. Choi, B. J. Yang, G. N. Bae and J. H. Jung, ACS Appl Mater Interfaces 2015, 7, 25313-25320.

[24] S. A. Lim and M. U. Ahmed, Biosens Bioelectron 2015, 70, 48-53.

[25] Wang G., Shen X., Horvat J., Wang B., Liu H., David W. and J. Y., J, phys. chem. C 2009, 113, 
4357-4361.

[26] M. A. Pimenta, G. Dresselhaus, M. S. Dresselhaus, L. G. Cancado, A. Jorio and R. Saito, Phys Chem Chem Phys 2007, 9, 1276-1291.

[27] Y. Fan, J.-H. Liu, H.-T. Lu and Q. Zhang, Microchimica Acta 2011, 173, 241-247.

[28] O. J. D’Souza, R. J. Mascarenhas, T. Thomas, I. N. N. Namboothiri, M. Rajamathi, P. Martis and J. Dalhalle, Journal of Electroanalytical Chemistry 2013, 704, 220-226.

[29] R. Moradi, S. A. Sebt, H. Karimi-Maleh, R. Sadeghi, F. Karimi, A. Bahari and H. Arabi, Phys Chem Chem Phys 2013, 15, 5888-5897.

[30] D. Ye, L. Luo, Y. Ding, B. Liu and X. Liu, Analyst 2012, 137, 2840-2845.

[31] Samira B., Fereshteh C. and S. B. A. H., Russian Jouranl of Electrochemistry 2014, 50, $947-952$.

[32] S. Zhu, J. Zhang, X.-e. Zhao, H. Wang, G. Xu and J. You, Microchimica Acta 2013, 181, 445-451.

[33] T. Thomas, R. J. Mascarenhas, O. J. D'Souza, P. Martis, J. Dalhalle and B. E. Swamy, J Colloid Interface Sci 2013, 402, 223-229. 
Table 1 Comparison of major characteristics at different carbon based modified electrodes for Ltryptophan‘s determination

\begin{tabular}{|c|c|c|c|}
\hline Modified electrodes & Linear working & Detection limit & Ref. \\
\hline & range $(\mu \mathrm{M})$ & $(\mu \mathrm{M})$ & \\
\hline \multirow[t]{2}{*}{$\mathrm{Mg}-\mathrm{Al} \mathrm{LDH} / \mathrm{MWCNT} / \mathrm{CPE}^{\mathrm{a}}$} & $3-90$ & 0.0068 & [28] \\
\hline & $90-1000$ & & \\
\hline $\mathrm{FePt} / \mathrm{CNT} / \mathrm{CPE}^{\mathrm{b}}$ & $5-500$ & 1 & [29] \\
\hline $\mathrm{Co}_{3} \mathrm{O}_{4} / \mathrm{GR} / \mathrm{Nafion} / \mathrm{GCE}^{\mathrm{c}}$ & $0.05-10$ & 0.01 & [30] \\
\hline $\mathrm{TiO}_{2}-\mathrm{MWNT} / \mathrm{GCE}^{\mathrm{d}}$ & $1-150$ & 0.52 & [31] \\
\hline $\mathrm{SWCNH} / \mathrm{GCE}^{\mathrm{e}}$ & $0.5-50$ & 0.05 & [32] \\
\hline MWCNT/CPE & $0.6-9$ & 0.03 & [33] \\
\hline $\mathrm{Co}_{3} \mathrm{O}_{4}-\mathrm{CNF} / \mathrm{GCE}$ & $0.005-40$ & 0.002 & This \\
\hline
\end{tabular}

a. $\mathrm{Mg}-\mathrm{Al} \mathrm{LDH} / \mathrm{MWCNT/CPE}$ : multiwall carbon nanotube/Mg-Al layered double hydroxide modified carbon paste electrode.

b. FePt/CNT/CPE: FePt decorated carbon nanotube nanocomposites modified carbon paste electrode.

c. $\mathrm{Co}_{3} \mathrm{O}_{4} / \mathrm{GR} / \mathrm{Nafion} / \mathrm{GCE}: \mathrm{Co}_{3} \mathrm{O}_{4}$ nanoparticles decorated graphene composite modified glassy carbon electrode.

d. $\mathrm{TiO}_{2}-\mathrm{MWNT} / \mathrm{GCE}: \mathrm{TiO}_{2}$ nanoparticles decorated multiwall carbon nanotube modified glassy carbon electrode.

e. SWCNH/GCE: single wall carbon nano-horn modified glassy carbon electrode.

f. MWCNT/CPE: multiwall carbon nanotube modified carbon paste electrode. 
Table 2 Results of interference experiments on the current intensity of $10 \mu \mathrm{M} \mathrm{L}-$ tryptophan on $\mathrm{Co}_{3} \mathrm{O}_{4}-\mathrm{CNF} / \mathrm{GCE}$.

\begin{tabular}{lclc}
\hline Interferences & Concentration $(\mu \mathrm{M})$ & Current ratio & R.S.D \\
\hline Leucine & 10 & 0.96 & $2.65 \%$ \\
Threonine & 10 & 0.97 & $2.39 \%$ \\
Alanine & 10 & 0.96 & $1.04 \%$ \\
Glucose & 10 & 0.97 & $0.817 \%$ \\
Phenylalanine & 10 & 0.96 & $2.21 \%$ \\
Lysine & 10 & 0.97 & $2.55 \%$ \\
Sucrose & 10 & 0.97 & $0.686 \%$ \\
Tyrosine & 10 & 0.86 & $2.61 \%$ \\
\hline
\end{tabular}

Table3. Results of real sample analysis at $\mathrm{Co}_{3} \mathrm{O}_{4}-\mathrm{CNF} / \mathrm{GCE}$

\begin{tabular}{llllll}
\hline No. & Detected $(\mu \mathrm{M})$ & Added $(\mu \mathrm{M})$ & Found $(\mu \mathrm{M})$ & Recovery & R.S.D \\
\hline 1 & 1.74 & 2 & 2.09 & $105 \%$ & $1.03 \%$ \\
2 & 1.76 & 4 & 4.05 & $101 \%$ & $2.29 \%$ \\
3 & 1.80 & 6 & 6.10 & $102 \%$ & $4.46 \%$ \\
\hline
\end{tabular}




\section{Figure Captions:}

Fig. $1 \mathrm{~A}$ SEM of $\mathrm{Co}_{3} \mathrm{O}_{4}-\mathrm{CNF}$, inset is the amplified photo, B SEM of $\mathrm{Co}_{3} \mathrm{O}_{4}, \mathrm{C} \mathrm{XRD}$ of $\mathrm{Co}_{3} \mathrm{O}_{4}-\mathrm{CNF}$ and $\mathrm{Co}_{3} \mathrm{O}_{4}$, D Raman spectrum of $\mathrm{Co}_{3} \mathrm{O}_{4}-\mathrm{CNF}$ and $\mathrm{Co}_{3} \mathrm{O}_{4}$, all data were acquired at $514.5 \mathrm{~nm}$ excitation.

Fig. 2 A CV pattern of $10 \mu \mathrm{M}$ L-Trp on bare GCE, $\mathrm{Co}_{3} \mathrm{O}_{4} / \mathrm{GCE}, \mathrm{CNF} / \mathrm{GCE}$ and $\mathrm{Co}_{3} \mathrm{O}_{4}-\mathrm{CNF} / \mathrm{GCE}$ in phosphate solution (pH 2), B EIS plots of bare GCE ( $\mathbf{O})$ and $\mathrm{Co}_{3} \mathrm{O}_{4}-\mathrm{CNF} / \mathrm{GCE}(\boldsymbol{\square})$ in $5.0 \mathrm{mM}$ [Fe(CN)6]3-/4- solution containing $0.1 \mathrm{M} \mathrm{KCl}$.

Fig. $3 \mathrm{CVs}$ of $\mathrm{Co}_{3} \mathrm{O}_{4}-\mathrm{CNF} / \mathrm{GCE}$ in $0.1 \mathrm{M}$ phosphate buffer (pH 2) with $10 \mu \mathrm{M}$ L-Trp at scan rate ranging from 10 to $200 \mathrm{mV} \mathrm{s}^{-1}$. Inset are the linear regression of scan rate versus oxidation potential and current signal.

Fig. $4 \mathrm{~A} \mathrm{CV}$ of $10 \mu \mathrm{M}$ L-Trp at $\mathrm{Co}_{3} \mathrm{O}_{4}-\mathrm{CNF} / \mathrm{GCE}$ in $0.1 \mathrm{M}$ phosphate buffer $\mathrm{pH}(2-8)$ at scan rate of $100 \mathrm{mV} \mathrm{s}^{-1}$, B the current intensity of $10 \mu \mathrm{M}$ L-Trp at $\mathrm{Co}_{3} \mathrm{O}_{4}-\mathrm{CNF} / \mathrm{GCE}$ under different $\mathrm{pH}$ range from 2-8, $\mathrm{C}$ oxidation potential of $10 \mu \mathrm{M}$ L-Trp at $\mathrm{Co}_{3} \mathrm{O}_{4}-\mathrm{CNF} / \mathrm{GCE}$ under different $\mathrm{pH}$ range from 2-8, D current intensity of $10 \mu \mathrm{M}$ L-Trp at $\mathrm{Co}_{3} \mathrm{O}_{4}-\mathrm{CNF} / \mathrm{GCE}$ in $\mathrm{pH} 2$ under different deposition potential from $1.6 \mathrm{~V}$ to $2.0 . \mathrm{V}$

Fig. 5 A I-T pattern of L-Trp on $\mathrm{Co}_{3} \mathrm{O}_{4}-\mathrm{CNF} / \mathrm{GCE}$ in $\mathrm{pH} 2$ in the range of $0.005 \mu \mathrm{M}$ to $40 \mu \mathrm{M}$, the insert is the I-T pattern of L-Trp in low concentration. B the linear regression of L-Trp is in the range of $0.005 \mu \mathrm{M}$ to $40 \mu \mathrm{M}$.

Scheme 1 The mechanism of electrochemical oxidation process of tryptophan 


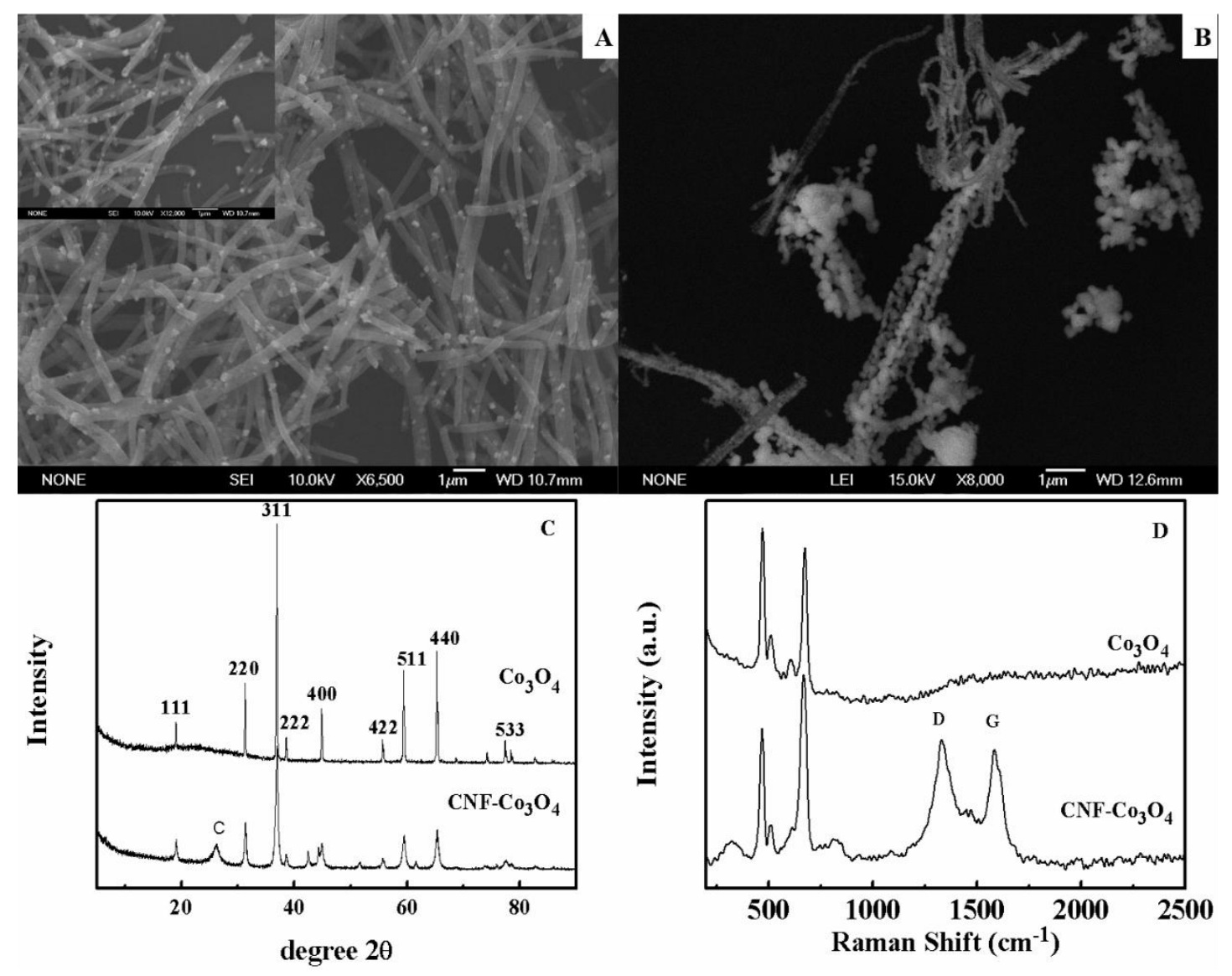

Fig. 1 

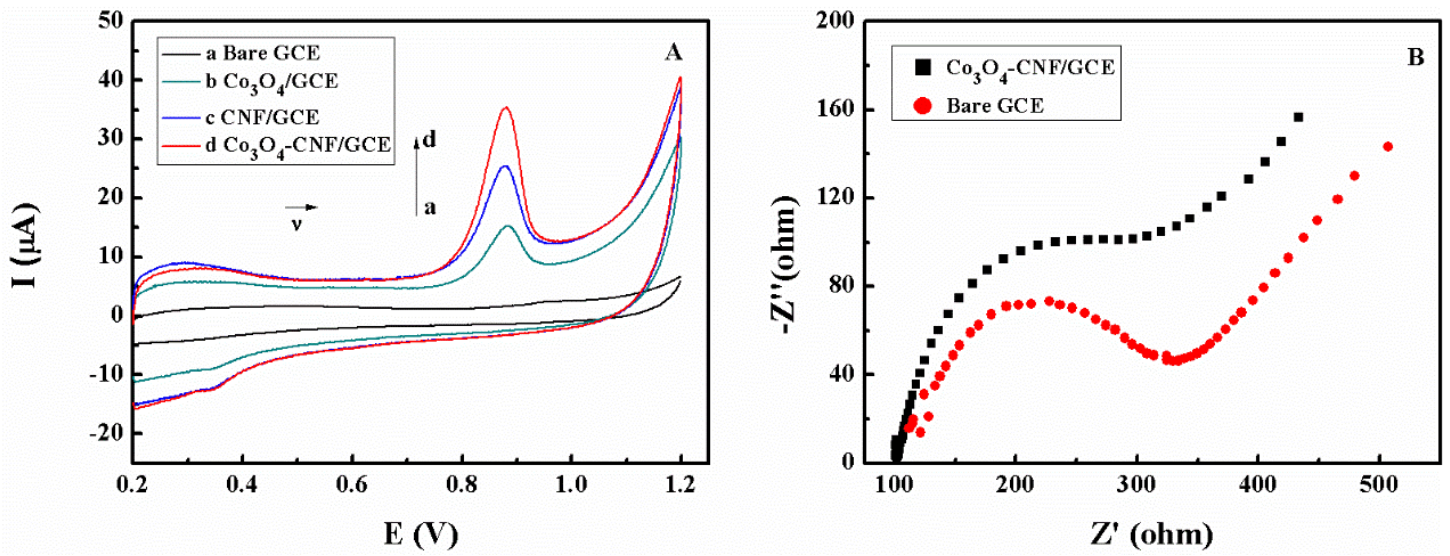

Fig. 2 


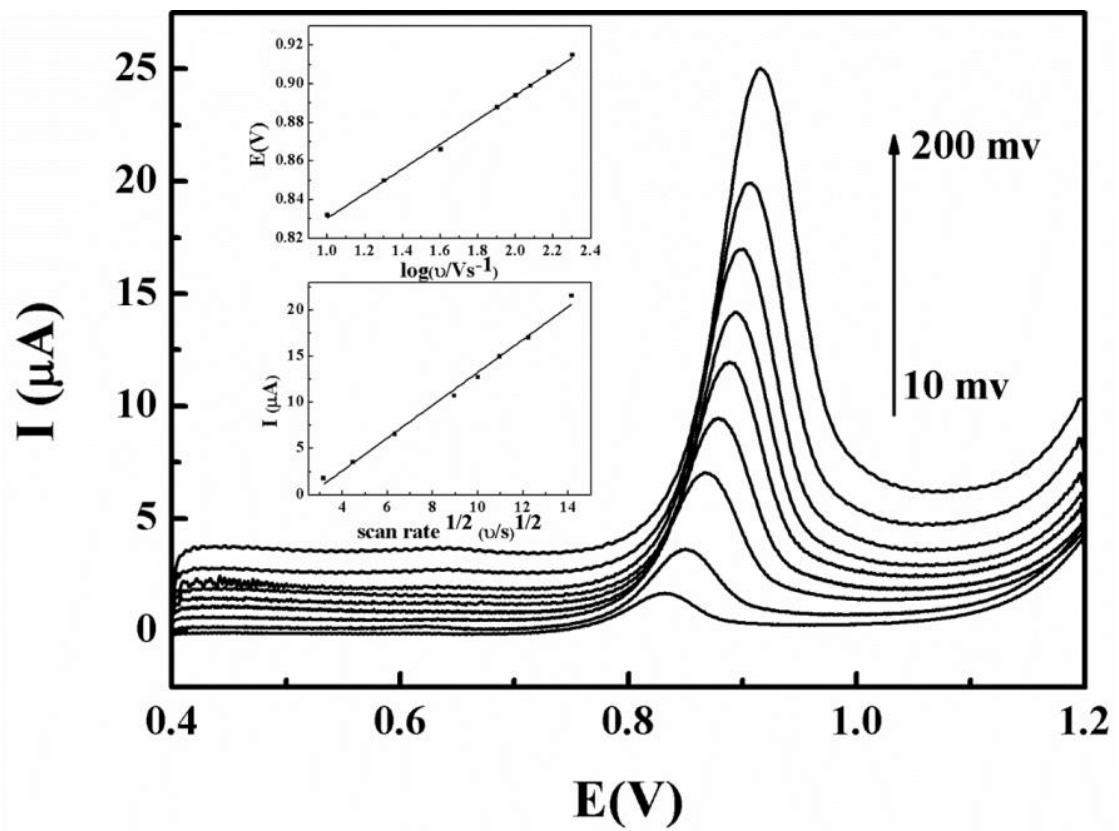

Fig. 3 

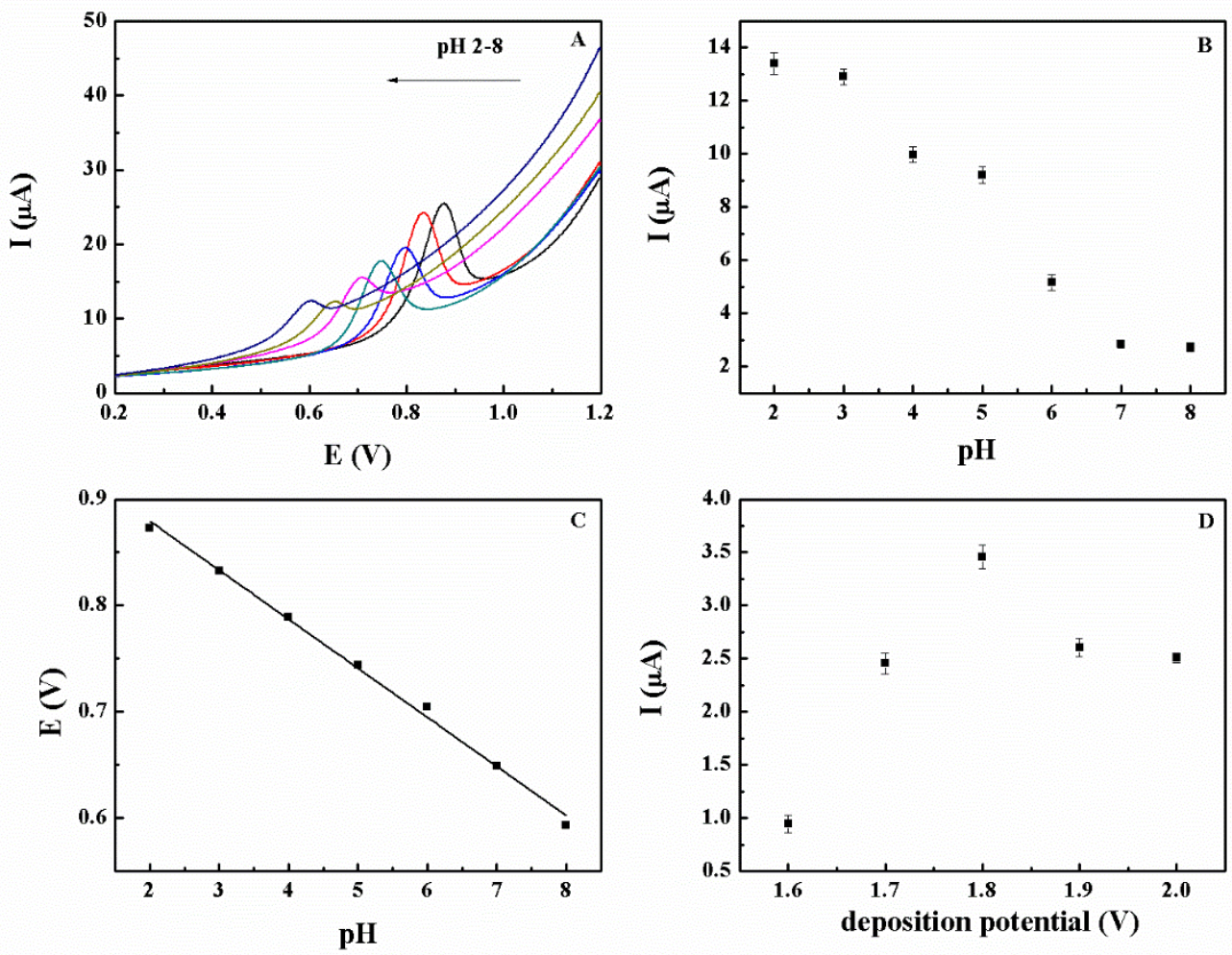

Fig. 4 

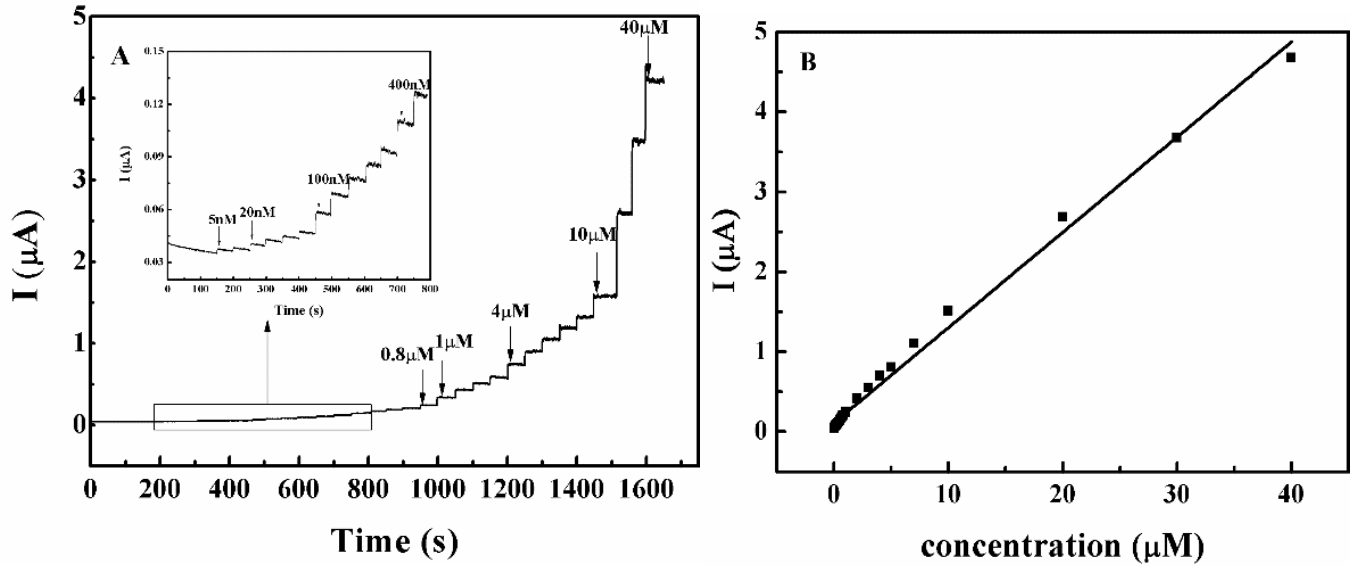

Fig. 5 


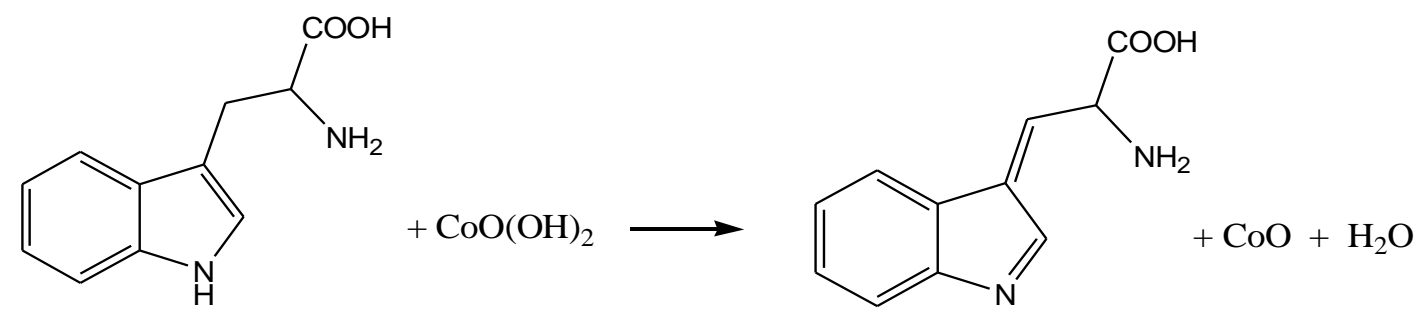

Sheme 1 


\section{Author Biography}

Prof. Yaping Ding gained her Ph.D degree in the University of Science and Technology of China and teaches in Shanghai University College of Science. She was also hired as professor in School of Materials Science and Engineering and worked as research leader in there. She is now interesting in synthesizing nano-materials and bio-functional material for electrochemical sensing.

Mr. Shengdong Zhao is a Ph.D candidate in School of Materials Science and Engineering. He is interesting in synthesizing nanomaterial and functional materials for different usage as supercapacitor, catalyst supporter and filter.

Miss Youlan Lu is a graduate student in Shanghai University, College of Science. She is now researching in the field of electrospining carbon based materials. She has been worked in carbon nanofibers' synthesizing, characterizing and modification for three years. She is interesting in synthesizing nano-materials exploring their bio-chemical usage.

Miss Rong Fu is a first year graduate student in Shanghai University, College of Science. She is working in the field of electrospining carbon nanofibers. She is interesting in synthesizing flexible carbon nanofiber mat and exploring their electrochemical usage. 